Auf Verlegers Rappen 


\title{
Auf Verlegers Rappen
}

\author{
Verlagsvertreter berichten von ihren \\ Begegnungen mit Buchhändlern, Verlegern \\ und Autoren
}

Herausgegeben von Hans Jordan

Zweite, erweiterte Auflage

Verlag J.B. Metzler

Stuttgart · Weimar 
Die Deutsche Bibliothek - CIP-Einheitsaufnahme

Auf Verlegers Rappen : Verlagsvertreter berichten von ihren Begegnungen mit Buchhändlern, Verlegern und Autoren / hrsg. von Hans Jordan. - 2., erw. Aufl. - Stuttgart; Weimar: Metzler, 1994 ISBN 978-3-476-01239-5

NE: Jordan, Hans [Hrsg.]

ISBN 978-3-476-01239-5

ISBN 978-3-476-03549-3 (eBook)

DOI 10.1007/978-3-476-03549-3

Dieses Werk einschließlich aller seiner Teile ist urheberrechtlich geschützt. Jede Verwertung außerhalb der engen Grenzen des Urheberrechtsgesetzes ist ohne Zustimmung des Verlages unzulässig und strafbar. Das gilt insbesondere für Vervielfältigungen, Übersetzungen, Mikroverfilmungen und die Einspeicherung und Verarbeitung in elektronischen Systemen.

(C) 1994 Springer-Verlag GmbH Deutschland

Ursprünglich erschienen bei J.B. Metzlersche Verlagsbuchhandlung und Carl Ernst Poeschel Verlag GmbH in Stuttgart 1994 


\title{
Inhalt
}

\author{
HANS JORDAN \\ Vorwort zur zweiten Auflage \\ Seite 1 \\ SiEgFRIED LENZ \\ Mit Hans Jordan auf Lesereise \\ Seite 3
}

HeINRICH MaRIA LeDIG-Rowohlt

Eiertänze und Dackelschwänze

Seite 6

HANS JORDAN

Erinnerungen an Heinrich Maria Ledig-Rowohlt

Seite 13

Peter Meuer

Herr Dulk kommt

Seite 25

HEInZ SARKOWSKI

Der Verlagsvertreter - historisch

Seite 31

WaLter BANGer

Der Verlagsvertreter - Aufgaben und Arbeitsweise

Seite 47

FRANZ BeCHER

Buchhändler, Verlagsvertreter, Mädchen für alles

Seite 55

Werner Classen

Keiner zu klein, Verleger zu sein

Seite 72 
KARL DRUCKLIEB

Pünktchen und Anton - oder: Nein, ich habe es nicht bereut! Seite 79

EDWIN GANTERT

Ich kann als Vertreter "wahr" sein

Seite 91

HANS-Gustav HaRKSEN

Kein Gänsebraten

Seite 103

Hans Haustein

Vom Pressezeichner und -fotografen zum Vertreter

Seite 109

HANS JORDAN

Wie ich Verlagsvertreter wurde

Seite 123

Hans Jochen KeHRL

Die Praxis

Seite 149

HANSJÖRg KIESER

Allerlei von gestern und vorgestern

Seite 161

PARIDAM VON DEM KNESEBECK

Die Ahnen - Wie hat es angefangen?

Seite 171

Paul Johannes SchindleR

Als Markthelfer unterwegs

Seite 178

DOROTHEe SCHINDLER

Die Überraschung

Seite 188 


\author{
IRENE ThoRnEWILL-TRAuMANN \\ Frau unterwegs \\ Seite 191 \\ Peter WÄLdE \\ Vom Grenzgänger zum Verlagsvertreter \\ Seite 197 \\ PaUl WiLd \\ Wie wird man Verlagsvertreter? \\ Seite 204 \\ WILL ZaCHAU \\ Das Buch müßte erfunden werden ... \\ Seite 222
HANS JORDAN
Nachwort
Seite 237 \\ Die Autorinnen und Autoren \\ Seite 239 \\ Register \\ Seite 249
}


In dankbarer Erinnerung an meine Frau 


\section{Vorwort zur zweiten Auflage}

Der geistige Vater dieses Buches ist der Frankfurter Buchhändler Heinrich Cobet. Er war es, der mich noch während meiner Reisezeit und später im Dürkheimer Kreis aufforderte, ein Buch über meine Reiseerlebnisse zu schreiben. Zeitmangel sowie die Tatsache, daß ich mich mündlich besser und lieber mitteile als schriftlich, verhinderten zunächst die Verwirklichung seiner gutgemeinten Anregung. Da Cobet bei jedem Treffen der "Dürkheimer" wieder auf diese Idee zu sprechen kam, griff ich eines Tages doch zur Feder. Schon bei den ersten Versuchen wurde mir aber klar, daß meine eigenen buchhändlerischen Erlebnisse und Reiseerfahrungen nicht ausreichen würden, um ein Buch zu füllen. So lag der Gedanke nahe, einige Kollegen sowie den von mir jahrelang betreuten Autor Siegfried Lenz und meinen alten Verlegerfreund Heinrich Maria Ledig-Rowohlt um Beiträge zu bitten. Es sollte ein umfassendes Buch über die Aufgaben, die Arbeit, das Leben und die Erlebnisse des Verlagsvertreters zustande kommen.

Die erste Auflage erschien 1986 im Franz Ehrenwirth Verlag in München; das Buch war von dem damaligen Verlagsleiter Frank Auerbach angenommen, wegen seines Ausscheidens aus diesem Verlag aber lektoratsmäßig leider nicht mehr betreut worden. Seit einigen Jahren ist das Buch vergriffen. Nachdem es heute keine andere Veröffentlichung über den für den ganzen Buchhandel immer wichtiger werdenden Berufsstand des Verlagsvertreters gibt, scheint mir eine Neuauflage angebracht, zumal mich im Laufe der Zeit eine Reihe von Anfragen erreichten, ob und wann das Buch wieder erscheint.

An dieser Stelle möchte ich Frank Auerbach besonders dafür danken, daß er eine Neuauflage nicht nur anregte, sondern auch aus Liebe zur Sache betreute. Ebenso bedanke ich mich beim Verlag J.B. Metzler, der das Buch als neue, erweiterte Ausgabe herausgebracht hat. In dieser sind einige Beiträge der Erstauflage nicht mehr enthalten und durch zahlreiche andere ersetzt worden. Neben den bisher 
vor allem anekdotisch geprägten Aufzeichnungen sind zusätzlich jetzt buchhändlerisch fachbezogene und buchhandelsgeschichtlich fundierte Artikel enthalten. Damit wird - wie ich hoffe - das Buch dem Anspruch eines Standardwerkes, das über unseren Berufsstand Auskunft gibt, noch besser gerecht.

HANS JORDAN

Juni 1994 